\title{
Correlation between SOX2 and Mutant IDH1 Protein Expression in Astrocytomas and their Clinicopathologic Significance
}

\author{
SAHAR F. MANSOUR, M.D.; ASMAA Y. IBRAHIEM, M.Sc.; MUHAMMAD A.A. MUHAMMAD, M.D. and \\ AMR A. KAMEL, M.D.
}

The Department of Pathology, Faculty of Medicine, Suez Canal University, Ismailia, Egypt

\begin{abstract}
Background: Recent advances in genomic analyses provide a comprehensive view of the tumour-to-tumour complexity of glioma. Subgroups have been defined based on distinct genetic and epigenetic alterations and gene expression profiles. IDH1gene mutation is among the first genetic alterations observed during the development of the glioma. SOX2 is a transcriptional co-factors that are associated with various developmental milestones and is over-expressed in tumours, It plays a role in maintaining pluripotency in several cancers.
\end{abstract}

Aim of Study: Evaluate the correlation between IHC expression of SOX2 and mutant IDH1 protein in astrocytomas and their clinicopathological significance.

Material and Methods: The study was conducted with 50 patients diagnosed as Astrocytomas at the pathology laboratory, Suez Canal University Hospital between 2003 to 2015. The clinicopathological data were obtained from medical records Each case was studied for IHC expression of SOX2 and mutant IDH1(R132H antibody) and correlate expression results with variable clinicopathological features.

Results: A statistically significant correlation between the expression of SOX2 and mutant IDH1 protein in astrocytomas and their expressions and grades of astrocytoma as, Glioblastoma multiform (GBM) showed prominent expression of (SOX2 and mutant IDH1 protein) than other astrocytoma grades. A statistically significant relation between mutant IDH1 protein expression and tumour location with more expression among a tumour at the frontal lobe but no a statistically significant relation between SOX2 expression and tumour location. A higher SOX2 expression was among female patients compared to male patients, with a statistically significant correlation. No a statistically significant correlation between the expression of mutant IDH1 protein and gender. No a statistically significant correlation between the expression of both SOX2 \& mutant IDH1 protein and age of the studied patients. A positive relationship between the expression of SOX2 and mutant IDH1 protein in the astrocytomas.

Correspondence to: Dr. Sahar F. Mansour, The Department of Pathology, Faculty of Medicine, Suez Canal University, Ismailia, Egypt
Conclusion: Expression of SOX2 and mutant IDH1 protein in astrocytomas mainly GBM suggest a role in tumour invasion and dedifferentiation of tumour cells in astrocytomas.

Key Words: Astrocytoma - SOX2 - IDH1.

\section{Introduction}

ASTROCYTOMAS are the most common type of primary brain tumor (gliomas) [1] . Malignant gliomas are the most common primary brain tumor, comprising more than 80 percent of all primary brain neoplasms [2]. Although the incidence of primary brain tumors is relatively low compared to other cancer types, primary brain tumors give rise to a disproportionate amount of morbidity and mortality, often causing debilitating impairment to patients' movement and speech [3]. Although primary CNS tumors comprise only $1.4 \%$ of all cancers, they are among the most aggressive tumors and result in a combined mortality rate of about $60 \%$ [4]. In fact, the five-year survival rate for primary malignant brain and central nervous system tumors is the sixth lowest among all types of cancers after pancreatic, liver \& intrahepatic bile duct, lung, stomach, and esophageal [5].

Astrocytomas are subdivided into grades I-IV as follows: Pilocytic, grade I; diffuse, grade II; anaplastic, grade III; and Glioblastoma Multiforme (GBM), grade IV [6].

Recent advances in genomic analyses provide us with a comprehensive view of the tumor-totumor complexity of gliomas. Subgroups have been defined based on distinct genetic and epigenetic alterations and gene expression profiles [7]. The specific phenotypes of tumors may depend on both the cells of origin and subsequent genetic and epigenetic alterations to these cells but our understanding of these matters is still incomplete [8]. 
Mutations in the isocitrate dehydrogenase genes IDH 1 and IDH2 are among the first genetic alterations observed during the development of lowergrade glioma (LGG) $[\mathbf{9 , 1 0}$. LGG-associated IDH mutations confer gain-of-function activity by converting a-ketoglutarate to the oncometabolite R2-hydroxyglutarate (2HG). Reduced availability of aKG and accumulation of $2 \mathrm{HG}$ by mutant IDH may coordinate genome-wide epigenetic changes phenotype, that predispose the cells toward malignant transformation [11,12] . According to the 2016 WHO central nervous system tumor classification, assessment of IDH mutation status is recommended for all patients with grades II and III gliomas, and in patients younger than 55 years with glioblastoma [13]. The most frequent IDH1 mutation can be detected by immunohistochemistry using the antiIDH antibody that recognises the R132H mutated protein [14]. Less frequent IDH1 and IDH2 mutations can only be identified by DNA sequencing. IDH1 testing by immunohistochemistry is a reliable diagnostic method with high sensitivity/specificity, combined with other advantages as compared to DNA sequencing (i.e., time and cost-effectiveness, ability to detect few single positive cells which can be missed by sequencing tests). IDH1 immunohistochemistry can be performed on fixed and paraffin embedded tissue samples. The sensitivity and specificity of immunohistochemistry are reported to be higher than that of sequencing [15] but the latter technique is useful for identifying the rarer mutations not identified by immunohistochemistry. If immunohistochemistry is negative or inconclusive in lower grade tumours or suspected secondary glioblastoma, direct sequencing of the IDH 1 by PCR-or next generation sequencing (NGS)-based methods should be carried out to screen for non-IDH1-R132H mutations. The choice of technique depends on laboratory expertise, equipment available for testing, and the clinician and pathologist's preference [16].

Glioma stem cells (GSCs) are defined as tumor cells capable of forming heterogeneous glial tumors [17]. They are endowed with specific properties including high tumorigenic ability, unlimited selfrenewal potential, and capacity for multipotent differentiation, e.g., generating a diversity of progeny $[18,19]$

Sex-determining region Y (SRY)-box (SOX) is an established stem cell "master" regulator highly expressed in multiple tissue stem cells, including various types of NS and progenitor cells [20]. SOX2 is an important transcription factor for maintenance of embryonic stem cell pluripotency and selfrenewal and plays a key role during organogenesis and in embryonic development [21]. Sox 2 is expressed in various phases of embryonic development and its expression has been studied in many human cancers, including breast, lung, colon, and nasopharyngeal carcinoma and hepatocellular carcinoma [22-24].

Aim of work:

This work aim to evaluate the correlation between IHC expression of SOX2 and IDH1 in astrocytomas and their clinicopathological significance.

\section{Patients and Methods}

Fifty patients who underwent a stereotactic biopsies from brain mass at Suez Canal UniversityHospital between 2003 and 2015, and had pathologically proven glioma diagnosis were enrolled in this study. The demographic data of all patients were recorded. Astrocytomas were graded according to WHO grading system (2008) [25], into four groups, 18 cases $(36 \%)$ were Glioblastoma multiform, 14 cases (28\%) were diffuse astrocytoma, 9 cases $(18 \%)$ were Anaplastic and 9 cases $18 \%$ were pilocytic astrocytoma.

\section{Immunohistochemistry:}

Formalin-fixed and paraffin wax-embedded Astrocytoma specimens obtained from 50 patients were investigated. Hematoxylin and eosin staining was used for the histological study, and one block with maximal section of tumoral tissue was chosen for immunostaining. The specimens were cut into 4-microm-thick sections, which were dewaxed and stained using the streptavidin-biotin-peroxidase complex method. For antigen retrieval, the slides were heated at $125 \mathrm{c}$ for 10 minutes for SOX2 staining. The sections were incubated with antibodies at the following dilutions: Anti- SOX2 antibodies (GeneTex) at 1:500 and anti-IDH1 monoclonal antibody(Dianova, Hamburg, Germany, clone H09) at 1:200, and negative control samples were incubated with PBS instead of the primary antibody for 2 hours at $4 \mathrm{C}$. After being washed three times with TBS, each slide was incubated for 5 minutes in $2 \%$ 3,3'-diaminobenzidine tetrahydrochloride $50 \mathrm{mM}$ tris-buffer ( $\mathrm{pH}$ 7.6) containing $0.3 \%$ hydrogen peroxidase as a chromogen, then counterstained with hematoxylin. Tumors with more than 5\% nuclear stained cancer cells were regard as being SOX2-positive [26]. Cytoplasmic intensity alone and/or along with nuclear staining were subjectively evaluated and was considered IDH1-positive. All sections were evaluated by a pathologist who was unaware of the clinical outcomes of the patients. 


\section{Statistical analysis:}

Data were be analyzed by SPSS v.11 computer package. These analyzes were performed using Fisher's, Chi-square, Spearman correlation coefficient and linear regression $(p<0.05)$.

\section{Results}

\section{I- Patients and clinicopathologic characteristics:}

This study was conducted on 50 cases of astrocytoma; 18 cases (36\%) were Glioblastoma multiform, 14 cases (28\%) were diffuse astrocytoma, 9 cases (18\%) were Anaplastic and 9 cases $18 \%$ were pilocytic astrocytoma (Figs. 1 a-4a). The age of the studied group ranged from 2 years to 71 year with a mean of 39.7. According to gender distribution, in our study, males were 29 with a ratio of $(58 \%)$ and females were 21 with a ratio of $(42 \%)$. According to the site distribution the most common site for astrocytoma was the parietal lobe $24 \%$ followed by Frontal and temporal lobe both were $16 \%$ followed by cerebellum $12 \%$ followed by post fossa, Fronto-temporal, Tempo-parietal and parietooocipital each with a ratio of $6 \%$. In pilocytic astrocytoma the most common site is the cerebellum 6 cases next to it is post fossa 3 cases (Table 1).

\section{II- Immunohistochemical:}

- Expression mutant IDH1 protein and clincopathological correlation:

In the present study, human endometrial tissue served as positive control for mutant IDH1 protein immunostaining, a diffuse cytoplasmic staining was noted, immunoreactiviy was observed in the cytoplasm, normal brain tissue seen at the periphery of the tumor was considered as negative internal control. In our study mutant IDH1 protein staining pattern and immunoscore was different among various WHO grade astrocytomas being mainly diffuse cytoplasmic and nuclear staining was noted with higher grades.Cytoplasmic (and less nuclear) IDH1 mutant protein was expressed in $66 \%$ of the studied cases and was negative in $34 \%$ of the cases and showing moderate to strong expression in $42 \%$ of cases and mild expression in only $24 \%$. (Figs. 1b-4b). Regarding the correlation between IDH1 expression and variable clinicopathological features were summarized in Table (2). No statistically significant differences between IDH 1expression and gender \& age of patients According to each WHO grade, the IDH1 mutant protein expression positivity was related with WHO grades as detected mainly in most GBM (Grade IV) (83\%), followed by anaplastic astrocytoma (Grade II) (78\%), diffuse astrocytoma (Grade II) (64\%) with a statistically significant relation between WHO Grade of astrocytomas and IDH1 mutant protein expression. In our study IDH1 mutant immunostaining pattern and immunoscore was different among various WHO grade astrocytomas. More staining intensity was detected in high grades while weak intensity was observed among low grade astrocytomas. IDH1 mutant immunostaining pattern was mainly diffuse cytoplasmic and nuclear staining in high grades (anaplastic \& GBM), while cytoplasmic (rare weak nuclear) was noted in low grades (pilocytic \& diffuse (fibrillary). A statistically significant relation between IDH1 mutant protein expression and tumor location $(p=0.017)$ with more expression among the tumor originate at frontal lobe followed by temporal lobe and parietal lobe.

\section{- Sox2 Expression and clincopathological cor-} relation:

SOX2 expression is shown in (Fig. 5). SOX2 positive nuclei was expressed in (31/50 cases) $62 \%$ of the studied cases and was negative in (19/50 cases) $38 \%$ of the cases and expression showing was observed in 5\%-10\% in pilocytic astrocytomas, $10 \%-25 \%$ in diffuse astrocyomas both with low intensity. In anaplastic astrocytomas a strong expression intensity detected in $50 \%-70 \%$ of nuclei, and more prominent and strong expression in $75 \%$ $100 \%$ nuclei in GBM (mainly at high cell density area and perivascular cuffing cells). A higher SOX2 expression was reported among female patients compared to male patients, with a statistically significant correlation $(p=0.0039)$. In spite of higher expression of SOX2 expression in GBM than other grades, no statistically significant correlation can be detected. Also, no statistically significant correlation between SOX2 expression and other clinicopathological variables (as age, or location), (Table 3).

- Correlation between Expression of SOX2 and mutant IDH1 protein:

Using a simple linear regression showed the relationship between the expression of SOX 2 and mutant IDH1 protein $(\mathrm{R}=1)$, indicating a perfect linear relationship between the expression of these two markers in the astrocytomas of the study (Table 4). With prominent and strong positive immunostaining of both markers (SOX2 \& IDH1) among high grade astrocytomas (anaplastic and GBM) more than in low grade astrocytomas (pilocytic and diffuse fibrillary). 


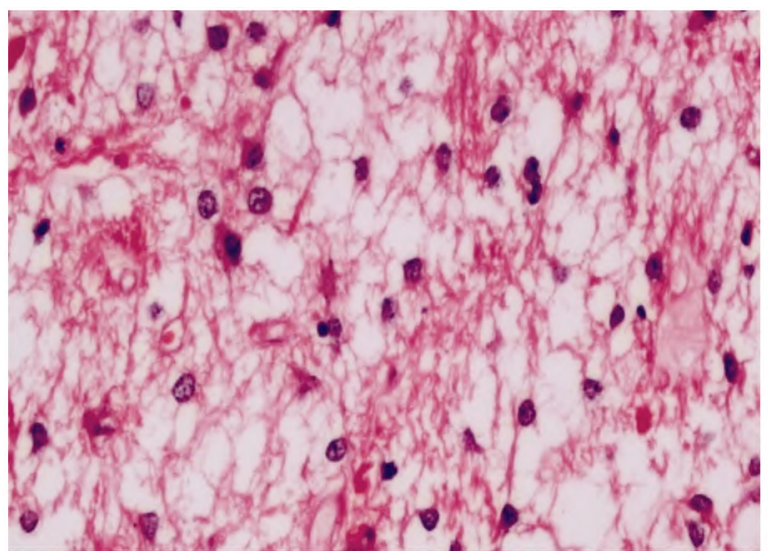

Fig. (1A): Pilocytic astrocytoma with microcystic areas (H\&E) (x400).

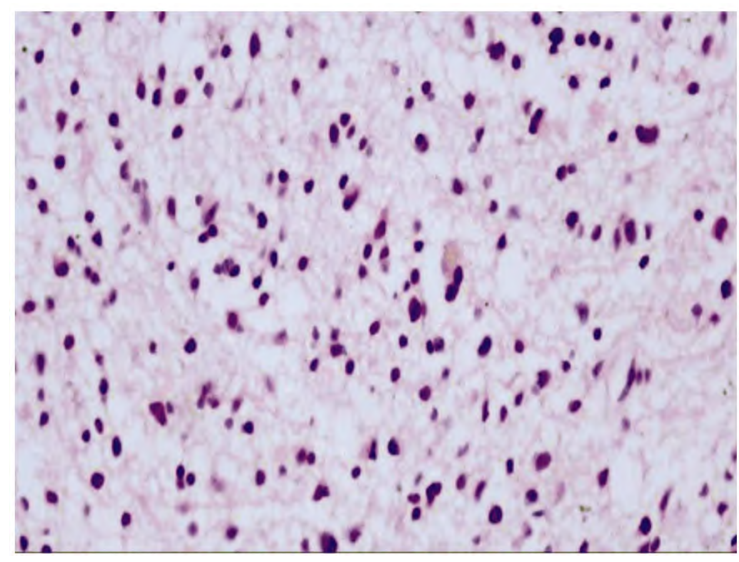

Fig. (2A): Diffuse fibrillary astrocytoma H\&E, note the fibrillary background (x400)

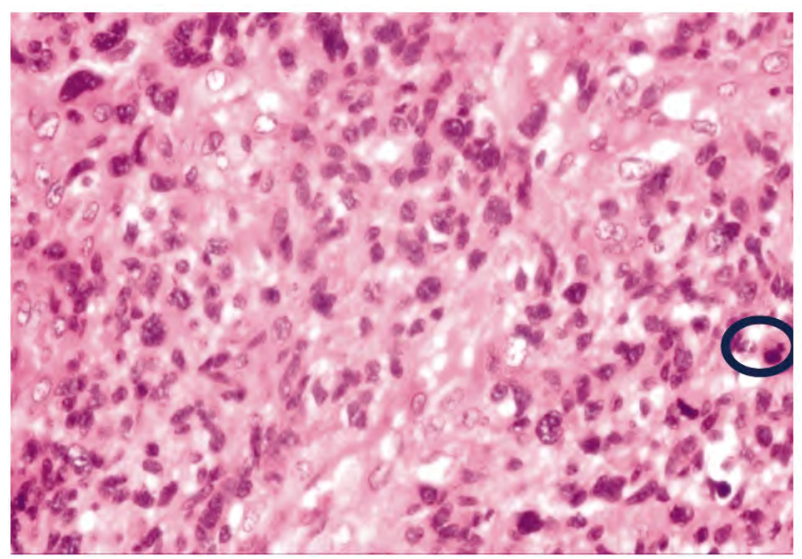

Fig. (3A): Anaplastic astrocytoma, (H\&E) note cellular and nuclear pleomorphism and mitosis (Blue circle) (x200).

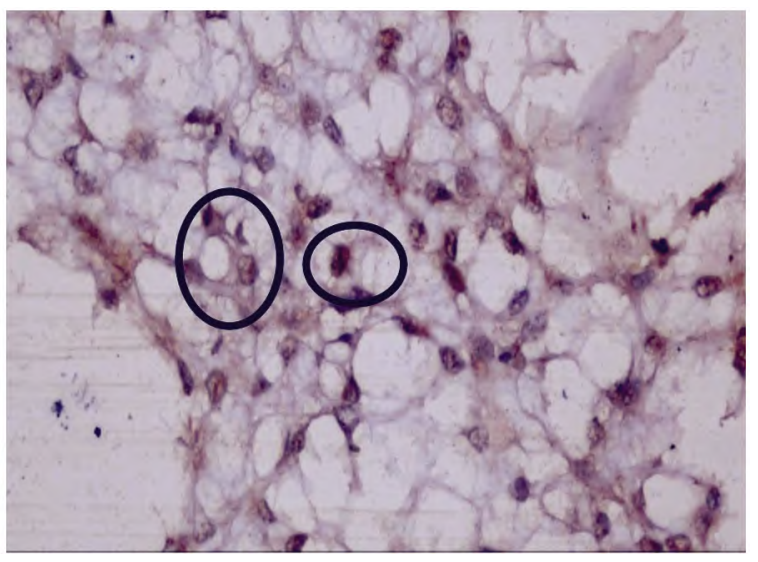

Fig. (1B): Pilocytic astrocytoma with microcystic areas showing mild cytoplasmic and nuclear mutant IDH1 protein positive staining $(\mathrm{x} 400)$.

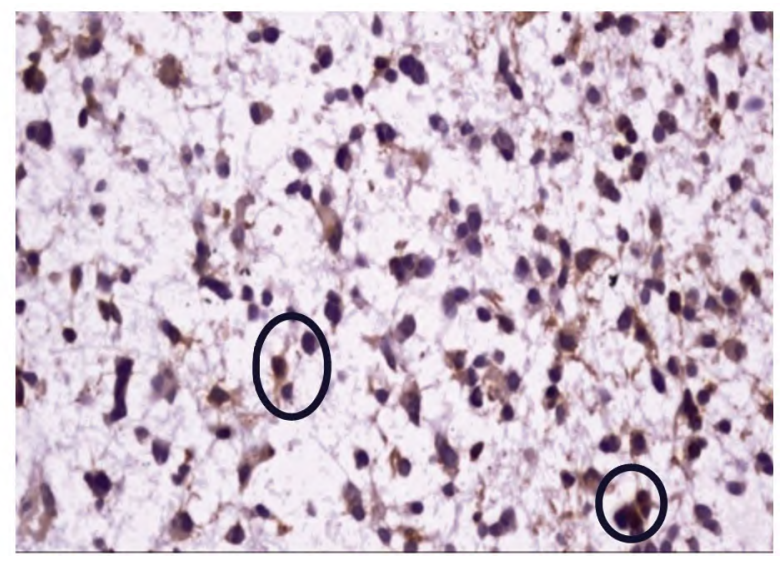

Fig. (2B): Diffuse fibrillary astrocytoma showing moderate cytoplasmic and nuclear mutant IDH1 protein immunostaining (x400).

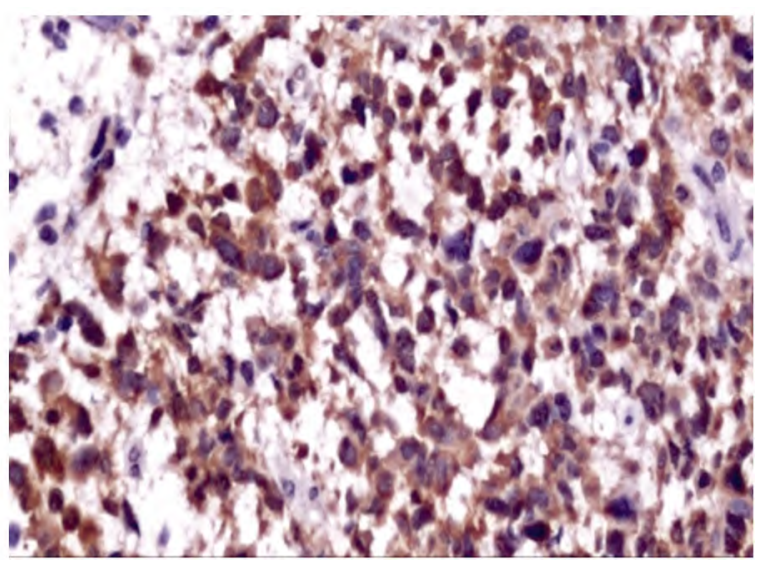

Fig. (3B): Anaplastic astrocytoma, positive cytoplasmic staining, mutant IDH1 protein immunoscore (+3) (x400). 


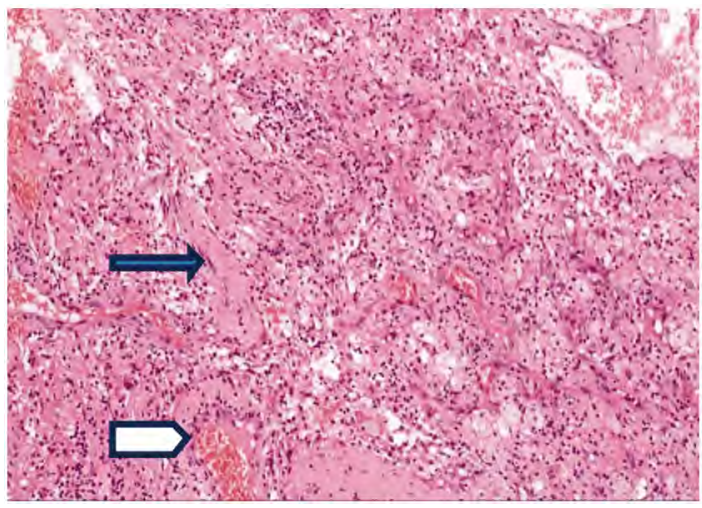

Fig. (4A): GBM H\&E; Showing necrosis (arrowhead) and glomeruloid body (arrow) (x200).

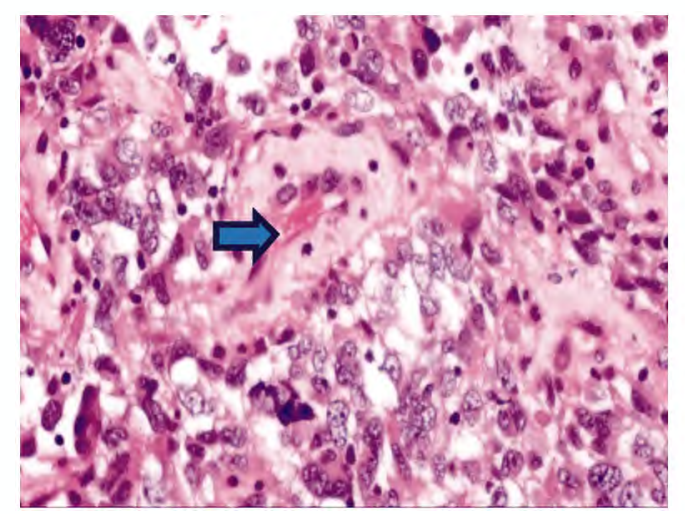

Fig. (5A): GBM Showing nuclear atypia and glomeruloid body (arrow) H\&E (x400).
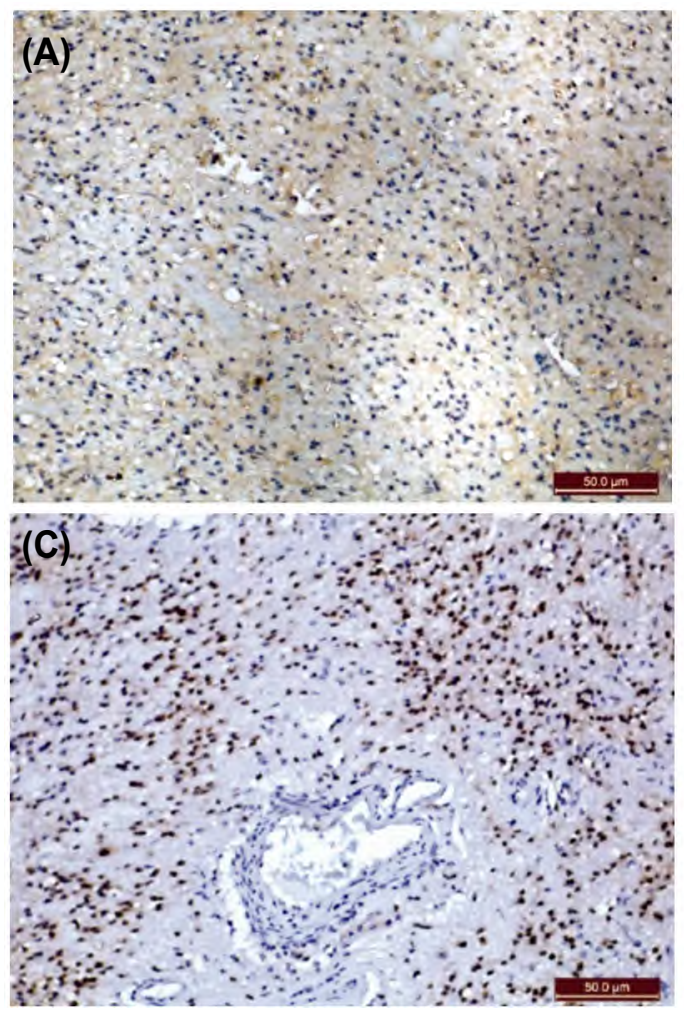

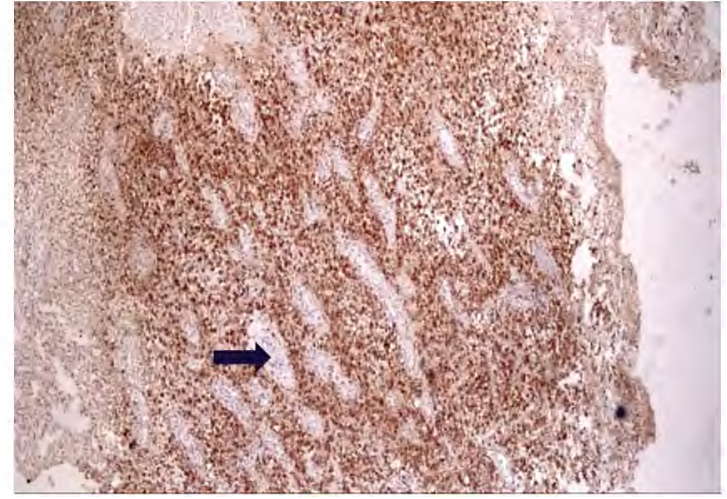

Fig. (4B): GBM; showing strong cytoplasmic and nuclear staining, glomeruloid body (arrow) note endothelial cells shows negative staining (x200).

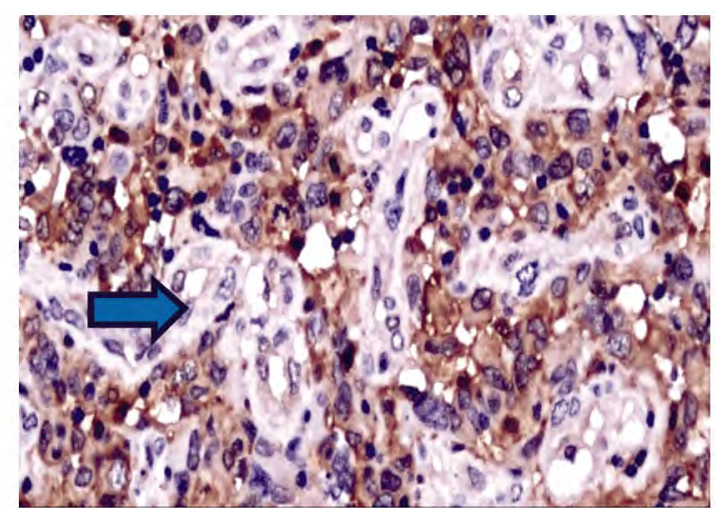

Fig. (5B): GBM showing moderate cytoplasmic and nuclear mutant IDH1 protein staining, note the glomeruloid body (arrow), note endothelial cells shows negative mutant IDH1 protein staining (x400).
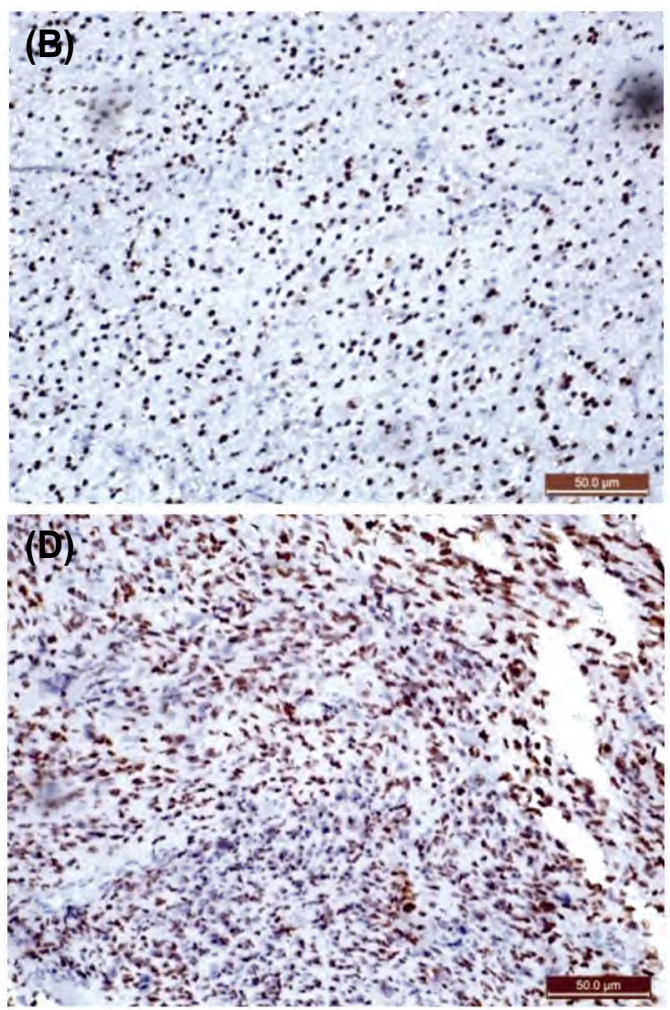

Fig. (6): SOX2 immunostainning, (A): Pilocytic astrocytoma with mild nuclear Sox2 positive staining (x200). (B): Diffuse fibrillary astrocytoma showing mild nuclear Sox2 positive staining (x200). (C): Anaplastic astrocytoma showing strong nuclear Sox2 positive staining (mainly at perivascular cuffinf cells) (x200). (D): GBM showing strong nuclear Sox2 positive staining (x200). 


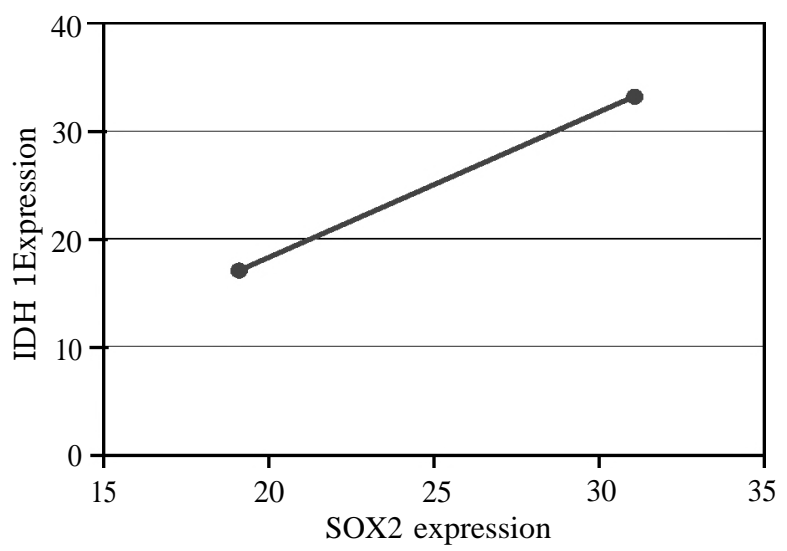

Fig. (7)

Table (1): Demographic and clinicopathological features of pateints $(n=50)$.

\begin{tabular}{llc}
\hline & Number & Percentage \\
\hline Gender: & 21 & \\
$\quad$ Female & 29 & 42 \\
Male & & 58 \\
Age: & 34 & \\
$\quad$ 550 Years & 16 & 32 \\
$\quad$ 50 Years & & \\
Location: & 8 & 16 \\
$\quad$ Frontal lobe & 12 & 24 \\
Parietal lobe & 8 & 16 \\
Temporal lobe & 2 & 1 \\
Occipital lobe & 6 & 12 \\
Cerebellum & 14 & 7 \\
Others & & \\
Grade (WHO) (Histopathology): & 9 & 18 \\
I (Pilocytic) & 14 & 28 \\
II (diffuse astrocytoma) & 9 & 18 \\
III (Anaplastic astrocytoma) & 18 & 36 \\
IV (Glioblastoma multiform) & 50 & 100 \\
\hline Total & & \\
\hline
\end{tabular}

Table (2): Correlation between mutant IDH1 protein expression (IHC) and clinicopathological features of patients.

\begin{tabular}{|c|c|c|c|c|c|}
\hline & \multicolumn{4}{|c|}{$\begin{array}{c}\text { Mutant IDH } 1 \text { protein } \\
\text { expression }\end{array}$} & \multirow{3}{*}{$\begin{array}{c}p- \\
\text { value }\end{array}$} \\
\hline & \multicolumn{2}{|c|}{ Positive } & \multicolumn{2}{|c|}{ Negative } & \\
\hline & $\mathrm{N}$ & $\%$ & $\mathrm{~N}$ & $\%$ & \\
\hline \multicolumn{6}{|l|}{ Gender: } \\
\hline Female & 13 & 62 & 8 & 38 & 0.603 \\
\hline Male & 20 & 69 & 9 & 31 & \\
\hline \multicolumn{6}{|l|}{ Age: } \\
\hline$<50$ Years & 23 & 68 & 11 & 32 & 0.28 \\
\hline$>50$ Years & 10 & 63 & 6 & 37 & \\
\hline \multicolumn{6}{|l|}{ Grade (Histopathology): } \\
\hline I pilocytic astrocytoma & 2 & 22 & 6 & 78 & 0.014.* \\
\hline II diffuse astrocytoma & 9 & 64 & 5 & 35 & \\
\hline III anaplastic astrocytoma & 7 & 78 & 2 & 22 & \\
\hline IV GBM & 15 & 83 & 3 & 17 & \\
\hline \multicolumn{6}{|l|}{ Location: } \\
\hline Frontal lobe & 8 & 100 & 0 & 0 & $0.017 *$ \\
\hline Parietal lobe & 10 & 83 & 2 & 17 & \\
\hline Temporal lobe & 7 & 88 & 1 & 12 & \\
\hline Occipital lobe & 1 & 50 & 1 & 50 & \\
\hline Cerebellum & 2 & 33 & 4 & 67 & \\
\hline Others & 4 & 31 & 9 & 69 & \\
\hline Total & 33 & 66 & 17 & 34 & \\
\hline
\end{tabular}

Table (3): Correlation between SOX2 expression (IHC) and clinicopathological features of patients.

\begin{tabular}{|c|c|c|c|c|c|}
\hline & \multicolumn{4}{|c|}{ SOX2 expression } & \multirow{3}{*}{$\begin{array}{c}p- \\
\text { value }\end{array}$} \\
\hline & \multicolumn{2}{|c|}{ Positive } & \multicolumn{2}{|c|}{ Negative } & \\
\hline & $\mathrm{N}$ & $\%$ & $\mathrm{~N}$ & $\%$ & \\
\hline \multicolumn{6}{|l|}{ Gender: } \\
\hline Female & 18 & 86 & 3 & 14 & $0.0039 * *$ \\
\hline Male & 13 & 45 & 16 & 55 & \\
\hline \multicolumn{6}{|l|}{ Age: } \\
\hline$<50$ Years & 22 & 65 & 12 & 35 & 0.7556 \\
\hline$>50$ Years & 9 & 56 & 7 & 44 & \\
\hline \multicolumn{6}{|l|}{ Grade (Histopathology): } \\
\hline I pilocytic astrocytoma & & 22 & 7 & 78 & 0.2 \\
\hline II diffuse astrocytoma & 5 & 35 & 11 & 65 & \\
\hline III anaplastic astrocytoma & 6 & 67 & 3 & 33 & \\
\hline IV GBM & 18 & 100 & 0 & 0 & \\
\hline \multicolumn{6}{|l|}{ Location: } \\
\hline Frontal lobe & 6 & 75 & 2 & 25 & 0.0913 \\
\hline Parietal lobe & 8 & 67 & 4 & 33 & \\
\hline Temporal lobe & 6 & 75 & 2 & 25 & \\
\hline Occipital lobe & 1 & 50 & 1 & 50 & \\
\hline Cerebellum & 4 & 67 & 2 & 33 & \\
\hline Others & 6 & 46 & 7 & 54 & \\
\hline Total & 31 & 62 & 19 & 38 & \\
\hline \multicolumn{6}{|c|}{$p$-value *=Statistically significant. } \\
\hline \multicolumn{6}{|c|}{$\begin{array}{l}\text { Table (4): Simple linear regression with two variants, SOX2 } \\
\text { and mutant IDH1 protein expression in studied } \\
\text { astrocytomas. }\end{array}$} \\
\hline Model R R Square & & isted I & & $\begin{array}{l}\text { Std. } \\
\text { the }\end{array}$ & $\begin{array}{l}\text { Error of } \\
\text { stimate }\end{array}$ \\
\hline 1.000 & & 6667 & & 0.7500 & $X+6.250$ \\
\hline
\end{tabular}

Predictors: (Constant), SOX2-expression.

Dependent Variable: Mutant IDH1 protein-expression.

\section{Discussion}

Astrocytomas are the most common type of primary brain tumor (gliomas) [1]. Although many important genetic alterations have been known in gliomas, new technologies have shed light onto novel discoveries in recent years. These genetic alterations are currently being used as biomarkers. A biomarker is a genetic/epigenetic or biochemical feature that can be assessed to indicate a particular diagnosis, prognosis, or response to treatment [27] Single point mutations in the metabolic genes IDH 1 and 2 were recently discovered in gliomas [28,29] According to the 2016 WHO central nervous system tumor classification, assessment of IDH mutation status is recommended for all patients with grades II and III gliomas, and in patients younger than 55 years with glioblastoma most frequent IDH1 mutation can be detected by immunohistochemistry using the anti-IDH antibody that recognises the $\mathrm{R} 132 \mathrm{H}$ mutated protein. IDH mutations are believed to be one of the initial mutations to occur in gliomas. Approximately $80 \%$ of grade 2 and grade 3 gliomas as well as secondary GBMs harbor 
a single amino acid missense mutation in IDH1 at arginine 132 [30]. The IDH2 mutation at arginine 172 is less common and is mutually exclusive with mutations in IDH1 [31].

In this study we evaluate the expression of two biomarkers (SOX2 and IDH1) using IHC in astrocytomas to assess their expression and correlation to clinicopathological variables.

IDH1 mutant protein was expressed in $66 \%$ of the studied cases of this study. A cytoplasmic (and less nuclear) immune-staining with IDH1 was detected. No statistically significant differences between mut. IDH1 protein expression and gender $\&$ age of patients. According to each WHO grade, the IDH1 mutant protein expression positivity was related with WHO grade as detected mainly in most GBM (Grade IV) (83\%), followed by anaplastic astrocytoma (Grade III) (78\%), diffuse astrocytoma (Grade II) (64\%) and finally pilocytic astrocytoma (Grade I) (22\%), with a statistically significant relation between IDH1 mutant protein expression and WHO Grade of astrocytomas. These findings confirm with other recent researches the role of IDH mutations early in the development of a astrocytomas and more during the progression of astrocytomas to high grade astrocytomas [32] .

In our study IDH1 mutant immunostaining pattern and immunoscore (was different among various WHO grade astrocytomas. More staining intensity was detected in high grades while weak intensity was observed among low grade astrocytomas. IDH1 mutant immunostaining pattern was mainly diffuse cytoplasmic and nuclear staining in high grades (anaplastic \& GBM), while cytoplasmic (rare weak nuclear) was noted in low grades (pilocytic \& diffuse (fibrillary). This finding related to that with higher grades as the perioxomes being translocated to the nucleus [33]. The immunostaining pattern and immunoscore of IDH1 (R132) simplifies the use of this variation for diagnostic purposes. For example, IDH mutation immunostaining could help distinguish pilocytic astrocytomas (WHO grade I) from diffuse astrocytomas (WHO grade II), since these lesions can sometimes be difficult to categorize solely on the basis of histopathological criteria [34] .

A statistically significant relation between IDH1 mutant protein expression and tumor location $(p=$ $0.017)$ with more expression among the tumor originate at frontal lobe followed by temporal lobe and parietal lobe. Other studies also observed that compared with IDH wild type, IDH1 mutant glio- mas were predominantly located in the frontal lobe

SOX2 is essential for normal pluripotent cell development and maintenance. SOX2 downregulation after embryogenesis is correlated with loss of pluripotency and self-renewal and knock-out of SOX2 in gliomas causes loss of tumorigenicity

Sox 2 positive nuclei was expressed in $62 \%$ of the studied cases. A higher SOX2 expression was reported among female patients compared to male patients, with a statistically significant correlation $(p=0.0039)$. No statistically significant correlation between SOX2 expression and other clinicopathological variables (as age, or location).

SOX2 positive expression was observed in 5\%$10 \%$ in pilocytic astrocytomas, $10 \%-25 \%$ in diffuse astrocyomas both with low intensity. Several studies have identified an overexpression of SOX2 in GBM patient samples. It was first found elevated in $90 \%$ of human biopsies studied at the mRNA and protein level in 2007. This research also showed that SOX2 expression was restricted to the nucleus [37].The higher expression of SOX2 in high-grade gliomas is consistent with the hypothesis that more aggressive disease harbors more mutations and a larger proportion of tumor cells with stem celllike properties [38]

In anaplastic astrocytomas a strong expression intensity detected in 50\%-70\% of nuclei, and more prominent and strong expression in $75 \%-100 \%$ nuclei in GBM (mainly at high cell density area and perivascular cuffing cells). In spite of higher expression of SOX2 expression in GBM than other grades, no statistically significant correlation can be detected. Guo et al., [39] used qRT-PCR and western blotting to demonstrate SOX2 expression in gliomas. Western blot analysis demonstrated that grade IV gliomas had greater SOX2 mRNA expression than grade II gliomas. Importantly, high levels of SOX2 have been associated with tumor aggressiveness and worse prognosis [40-42]. Gangemi et al., [43] reported high expression of SOX2 in high-grade gliomas using IHC and RT-PCR. They found that the expression of SOX2 was upregulated in tumor cells compared to normal brain tissue, but this was not statistically significant. It was not reported whether the expression detected with IHC was in accordance with the expression detected with RT-PCR. Gangemi et al., [43] examined 283 astrocytomas WHO grade II-IV and 52 recurrent tumors. Nearly half of the tumor cells were positive for SOX2 regardless of WHO grade. No association between SOX2 and survival was 
found in univariate or multivariate analyses. The regulation of SOX2 is a complex network of transcriptional, post-transcriptional, and post-translational regulators $[\mathbf{4 4 , 4 5 ]}$. Some of these regulators are altered in GBM and lead to the overexpression of SOX2. Four main signaling pathways are involved in SOX2 expression, including TGF- 3 SHH, EGFR, and FGFR. All these signaling pathways are aberrantly activated in GBM, which leads to the maintenance of the tumor at least in part through SOX2 factor overexpression. In the last years the mechanism of SOX2 activation in GBM has started to be unraveled. One group identified SOX2 gene amplification and promoter DNA hypomethylation in a set of GBM patients as the leading mechanism responsible for SOX2 aberrant expression [46]. SOX2 is also regulated transcriptionally and acts downstream relevant pathways in GBM formation. TGF- 3 regulates GSCs through SOX2 [47]. PDGF also modulates SOX2 activity. In fact, transforming activity of PDGF in neural progenitors and PDGFdependent tumors in mice triggered SOX2 expression [48]. In human GSCs, siRNA-induced downregulation of SOX2 confers sensitivity to treatment with PDGF and IGF 1 receptor inhibitors suggesting that resistance to PDGF and IGF1-receptor inhibitors in GBM are related to SOX2 expression [49].

In our study a more prominent and strong intensity of SOX2 nuclear immunostaining in anaplastic astrocytomas and GBM was observed mainly at high cell density area and perivascular cuffing cells. Yuan et al., [50] found that endothelial cells promoted the appearance of CSC-like glioma cells, as demonstrated by increases in tumourigenicity and expression of stemness genes such as Sox2, Olig2, Bmi 1 and CD 133 in glioma cells that were co-cultured with endothelial cells. Also out of glioma tissue specimens from 65 patients, found that the survival of glioma patients was closely correlated with the expression of both Shh by endothelial cells and Gli 1 by perivascular glioma cells. Taken together, this study demonstrates that endothelial cells in the tumour microenvironment provide Shh to activate the $\mathrm{HH}$ (Hedgehog) signalling pathway in glioma cells, thereby promoting GSC properties and glioma propagation [50].

The function of SOX2 has also been specifically characterized in GBM tumor-initiating cells [51] The silencing of SOX2 in human GBM cells transplanted in immunodeficient mice ceased cell proliferation and resulted in loss of tumorigenicity [52]. Gangemi et al., [43] also confirmed that the observed effect was due to SOX2 knockdown. Current research demonstrates a positive correlation between the expression of SOX2, OCT4, and NANOG and the pathological grade of gliomas. The aberrant expression of SOX2, OCT4, and NANOG may promote self-renewal as well as multilineage potential within GSCs. However, there is a possibility that these transcription factors may exhibit a distinct role in individual tumors, and the variation among different GBM subtypes and in GSM is as yet unexplored. It can also be hypothesized that the increased aggressiveness of recurrent GBM and the conversion to GSM that is sometimes seen is due to the enhancement of the GSC phenotype post-treatment [53]

In our study, using a simple linear regression showed the relationship between the expression of SOX2 and IDH1 markers ( $\mathrm{R}=1)$, indicating a perfect linear relationship between the expression of these two markers in the astrocytomas of the study. With prominent and strong positive immunostaining of both markers (SOX2 \&IDH1) among high grade astrocytomas (anaplastic and GBM) more than in low grade astrocytomas (pilocytic and diffuse fibrillary). Singh et al., [54] observed that all IDH1 mutant PDX lines also showed a predominance of SOX2 expression. This result is significant since it is widely accepted that the cellof-origin and compendium of genetic mutations of these initially low-grade (grade II, III) gliomas that progressed over several (2-10) years are fundamentally distinct from primary GBM. Taken together these results suggest that GICs, which are enriched in tumors arising from implanted primary glioma cells in mice are defined by high SOX2 expression irrespective of cellular origin or the history of tumor progression. The high expression of SOX2 in the PDX tumors, which were initiated by different driver oncogenes suggests that multiple oncogenic signaling pathways may converge to drive expression of this pluripotency transcription factor [54]. Importantly, in GBM, cellular metabolic characteristics are often genetically hardwired, such as recurrent IDH1mutations, which are commonly observed in proneural GBM. Mutant IDH1 leads to a gain-of-function enzymatic activity, causing accumulation of 2-hydroxyglutarate, an oncometabolite that inhibits the TET1 and TET2 demethylases to cause aberrant hypermethylation of DNA and histones. While the function of IDH1 mutations in the context of CSCs is not directly defined, IDH1 mutations induce a loss of differentiation, preventing the terminal differentiation of lineage-specific progenitors. Moving forward, integrated metabolomic and epigenomic profiling may reveal other examples of intricate relationships between metabolism and epigenetic programs and their influence on the glioma CSC state [55] 


\section{Conclusion:}

Expression of SOX2 and mutant IDH1 protein in astrocytomas mainly GBM suggest a role in tumour invasion and dedifferentiation of tumour cells in astrocytomas.

\section{References}

1- TAKAHASHI H.: Central nervous system tumor: Glioma. Gan To Kagaku. Ryoho., 42: 676- 677, 2015.

2- WRENSCH M., MINN Y., CHEW T., BONDY M. and BERGER M.S.: Epidemiology of primary brain tumors: Current concepts and review of the literature. Neuro. Oncol., 4: 278-299, 2002.

3- OSTROM Q.T., GITTLEMAN H., LIAO P., ROUSE C., CHEN Y. and DOWLING J.: CBTRUS statistical report: Primary brain and central nervous system tumors diagnosed in the United States in 2007-2011. Neuro. Oncol., 16 (Suppl 4): Iv1-63, 2014.

4- SURAWICZ T.S., DAVIS F., FREELS S., LAWS E.R. and MENCK HR. Brain tumor survival: Results from the National Cancer Data Base. J. Neurooncol., 40 (2): 15160, 1998.

5- TAKAHASHI H.: Central nervous system tumor: Glioma. Gan To Kagaku Ryoho., 42: 676-677, 2015.

6- PERRY A. and WESSELING P.: Histologic classification of gliomas. Handb. Clin. Neurol., 134: 71-95, 2016.

7- MOORE K. and KIM L.: Primary brain tumours: Characteristics, practical diagnos-tic and treatment approaches. In: Ray S.K., editor. Glioblastoma: Molecular Mechanisms of Pathogenesis and Current Therapeutic Strategies. New York: Springer Science+Business Media, LLC. p., 43-75, 2009.

8- SHACKLETON M., QUINTANA E., FEARON E.R. and MORRISON S.J.: Heterogeneity in cancer: Cancer stem cells versus clonal evolution. Cell., 138 (5): 822-9, 2009.

9- YAN H., PARSONS D.W., JIN G., MCLENDON R., RASHEED B.A., et al.: IDH1 and IDH2 mutations in gliomas. N. Engl. J. Med., 360: 765-773, 2009.

10- DANG L., WHITE D.W., GROSS S., BENNETT B.D., BITTINGER M.A., et al.: Cancer-associated IDH1 mutations produce 2-hydroxyglutarate. Nature., 462: 739-744, 2009.

11-VERHAAK R.G., HOADLEY K.A., PURDOM E., WANG V., QI Y., WILKERSON M.D.: Integrated genomic analysis identifies clinically relevant subtypes of glioblastoma charac-terized by abnormalities in PDGFRA, IDH1, EGFR, and NF1. Cancer. Cell., 17: 98-110, 2010.

12- TURCAN S., ROHLE D., GOENKA A., WALSH L.A., FANG F., et al.: IDH1 mutation is sufficient to establish the glioma hypermethylator phenotype. Nature 483: 479483,2012

13- FURNARI F.B., FENTON T., BACHOO R.M., et al.: Malignant astrocytic glioma: Genetics, biology, and paths to treatment. Genes. Dev., 21: 2683-2710, 2007.

14- COHEN A.L., HOLMEN S.L. and COLMAN H.: IDH1 and IDH2 mutations in gliomas. Curr. Neurol. Neurosci. Rep., 13: 345, 2013.
15- TAKANO S., TIAN W., MATSUDA M., YAMAMOTO T., ISHIKAWA E., KANEKO M.K., UAMAZAKI K., KATO Y. and MATSUMURA A.: Detection of IDH1 mutation in human gliomas: Comparison of immunohistochemistry and sequencing. Brain. Tumor. Pathol., 28: 115-123, 2011.

16- LEE D., SUH Y.L., KANG S.Y., PARK T.I., JEONG J.Y and KIM S.H.: IDH1 mutations in oligodendroglial tumors: Comparative analysis of direct sequencing, pyros equencing, immunohistochemistry, Nested PCR and PNAmediated clamping PCR. Brain. Pathol., 23: 285-293, 2013.

17- Cancer Genome Atlas Research Network. Comprehensive genomic characterization defines human glioblastoma genes and core pathways. Nature., 455: 1061-1068, 2008.

18- PARK D.M. and RICH J.N.: Biology of glioma cancer cells. Mol. Cells., 28:7-12, 2009.

19- SINGH S.K., HAWKINS C., CLARKE I.D., SQUIRE J.A., BAYANI J., HIDE T., HENKELMAN R.M., CUSIMANO M.D. and DIRKS P.B.: Identification of human brain tumour initiating cells. Nature., 432: 396-401, 2004.

20- FAVARO R., APPOLLONI I., PELLEGATTA S., SANGA A.B., PAGELLA P. and GAMBINI E.: Sox2 is required to maintain cancer stem cells in a mouse model of highgrade oligodendroglioma. Cancer. Res., 74: 1833-44, 2014.

21- TAKAHASHI K., OKITA K., NAKAGAWA M. and YAMANAKA S.: Induction of pluripo-tent stem cells from fibroblast cultures. Nat. Protoc., 2 (12): 3081-9, 2007.

22- YE F., LI Y., HU Y., ZHOU C., HU Y. and CHEN H.: Expression of Sox2 in human ovarian epithelial carcinoma. J. Cancer. Res. Clin. Oncol., 137: 13 1-7, 2011.

23- RUDIN C.M., DURINCK S., STAWISKI E.W., POIRIER J.T., MODRUSAN Z., SHAMES D.S., et al. Comprehensive genomic analysis identifies SOX2 as a frequently amplified gene in small-cell lung cancer. Nat. Genet., 44 (10): 1111-6, 2012.

24- STOLZENBURG S., ROTS M.G., BELTRAN A.S., RIVENBARK A.G., YUAN X. and QIAN H.: Targeted silencing of the oncogenic transcription factor SOX2 in breast cancer. Nucleic. Acids. Res., 40: 6725-40, 2012.

25- LOUIS D.N., OHGAKI H., WIESTLER O.D. and CAVENEE W.K., eds.: WHO classifcation of tumours of the central nervous system. 4th ed. Lyon, France: IARC Press, 2007.

26- BAREISS P.M., PACZULLA A., WANG H., SCHAIRER R., WIEHR S. and KOHLHOFER U.: SOX2 expression associates with stem cell state in human ovarian carcinoma. Cancer Res 73 :5544-55, 2013.

27- LEE J., SON M.J., WOOLARD K., et al.: Epigeneticmediated dysfunction of the bonemorphogenetic protein pathway inhibits differentiation of glioblastoma-initiating cells. Cancer. Cell., 13: 69-80, 2008.

28- LIU A., HOU C., CHEN H., ZONG X. and ZONG P.: Genetics and epigenetics of glioblastoma: Applications and overall incidence of IDH1 mutation. Front Oncol., 6: $16,2016$.

29- YAN H., et al.: IDH1 and IDH2 mutations in gliomas. $\mathrm{N}$. Engl. J. Med., 360 (8): 765-773, 2009. 
30- ICHIMURA K.: Molecular pathogenesis of IDH mutations in gliomas. Brain. Tumor. Pathol., 29 (3): 131-139, 2012.

31- WU G., DIAZ A.K., PAUGH B.S., et al.: St. Jude Children's Research Hospital-Washington University Pediatric Cancer Genome Project. The genomic landscape of diffuse intrinsic pontine glioma and pediatric non-brainstem highgrade glioma. Nat. Genet., 46: 444-450, 2014.

32- Cancer Genome Atlas Research Network Comprehensive, integrative genomic analysis of diffuse lower-grade gliomas. N. Engl. J. Med., 372 (26): 2481-2498, 2015.

33- ALLINI R., RICCI-VITIANI L., BANNA G.L., SIGNORE M., LOMBARDI D., et al.: Cancer stem cell analysis and clinical outcome in patients with glioblastoma multiforme. Clin. Cancer. Res., 14: 8205-8212, 2008.

34- METELLUS P., COLIN C., TAIEB D., GUEDJ E., NANNI-METELLUS I., et al.: 340 J. Neurooncol., 115: 333341, 2013.

35- OUAFIK L. and FIGARELLA-BRANGER D.: IDH mutation status impact on in vivo hypoxia biomarkers expression: New insights from a clinical, nuclear imaging and immunohistochemical study in 33 glioma patients. J. Neurooncol., 105: 591-600, 2011.

36- GANGEMI R.M., GRIFFERO F., MARUBBI D., et al.: SOX2 silencing in glioblastoma tumor-initiating cells causes stop of proliferation and loss of tumorigenicity. Stem. Cells, 27: 40-48, 2009.

37- HUANGFU D., OSAFUNE K., MAEHR R., GUO W., EIJKELENBOOM A., CHEN S., et al.: Induction of pluripotent stem cells from primary human fibroblasts with only Oct4 and Sox2. Nat. Biotechnol., 26 (11): 1269 75, 2008.

38- YUAN X., CURTIN J., XIONG Y., LIU G., WASCHSMANN-HOGIU S. and FARKAS D.L.: Isolation of cancer stem cells from adult glioblastoma multiforme. Oncogene 23: 9392-400, 2004.

39- GUO Y., LIU S., WANG P., ZHAO S., WANG F. and BING L.: Expression profile of embryonic stem cellassociated genes Oct. 4, Sox 2 and Nanog in human gliomas. Histopathology, 59: 763-75, 2011.

40- DONG C., WILHELM D. and KOOPMAN P.: Sox genes and cancer. Cytogenet Genome Res., 105 (2-4): 442-7, 2004.

41- SAIGUSA S., TANAKA K., TOIYAMA Y., YOKOE T., OKUGAWA Y., IOUE Y., et al.: Correlation of CD133, OCT4, and SOX2 in rectal cancer and their association with distant recurrence after chemoradiotherapy. Ann. Surg. Oncol., 16 (12): 3488-98, 2009.

42- CHEN Y., SHI L., ZHANG L., LI R., LIANG J., YU W., et al.: The molecular mechanism governing the oncogenic potential of SOX2 in breast cancer. J. Biol. Chem., 283 (26): 17969-78, 2008.

43- GANGEMI R.M.R., GRIFFERO F., MARUBBI D., PERERA M., CAPRA M.C., MALATESTA P., et al.: SOX2 silencing in glioblastoma tumor-initiating cells causes stop of proliferation and loss of tumorigenicity. Stem. Cells, 27 (1): 40-8, 2009.

44- AVILION A.A., NICOLIS S.K., PEVNY L.H., PEREZ L., VIVIAN N. and LOVELL-BADGE R.: Multipotent cell lineages in early mouse development depend on SOX2 function. Genes Dev., 17: 126-140, 2003.

45- FENG R. and WEN J.: Overview of the roles of SOX2 in stem cell and development. Biol. Chem., 396: 883$891,2015$.

46- STOLTZ K., SINYUK M., HALE J.S., WU Q., OTVOS B., WALKER K., VASANJI A., RICH J.N., HJELMELAND A.B. and LATHIA J.D.: Development of a SOX2 reporter system modeling cellular heterogeneity in glioma. Neuro. Oncol., 17: 361-371, 2015.

47- VELPULA K.K., DASARI V.R., TSUNG AJ, DINH D.H. and RAO J.S.: Cord blood stem cells revert glioma stem cell EMT by down regulating transcriptional activation of SOX2 and Twist1. Oncotarget., 2: 1028-1042, 2011.

48- ANNOVAZZI L., MELLAI M., CALDERA V., VALENTE G. and SCHIFFER D.: SOX2 expression and amplification in gliomas and glioma cell lines. Cancer Genomics Proteomics, 8 (3): 139-147, 2011.

49- ALONSO M.M., DIEZ-VALLE R., MANTEROLA L., RUBIO A., LIU D., CORTES-SANTIAGO N., URQUIZA L., JAUREGI P., LOPEZ de MUNAIN A., et al.: Genetic and epigenetic modifications of SOX2 contribute to the invasive phenotype of malignant gliomas. PLoS One, 6: e26740, 2011.

50- YUAN X., CURTIN J., XIONG Y. LIU G., WASCHSMANN-HOGIU S. and FARKAS D.L.: Isolation of cancer stem cells from adult glioblastoma multiforme. Oncogene, 23: 9392-400, 2004.

51- GUO Y., LIU S., WANG P., ZHAO S., WANG F., BING L.: Expression profile of embryonic stem cell-associated genes Oct. 4, Sox 2 and Nanog in human gliomas. Histopathology 59: 763-75, 2011.

52- MOORE N. and LYLE S.: Quiescent, slow-cycling stem cell populations in cancer: A review of the evidence and discussion of significance. J. Oncol., 1-11, 2011.

53- JACKSON M., HASSIOTOU F. and NOWAK A.: Glioblastoma stem-like cells: At the root of tumor recurrence and a therapeutic target. Carcinogenesis, 36: 177-85, 2015.

54- SINGH S.K., CLARKE I.D., TERASAKI M., BONN V.E., HAWKINS C. and SQUIRE J.: Identification of a cancer stem cell in human brain tumors. Cancer Res., 63: 5821-8. 11, 2003.

55- CLARKE M.F., DICK J.E., DIRKS P.B., EAVES C.J., JAMIESON C.H. and JONES D.L.: Cancer stem cellsperspectives on current status and future directions: AACR workshop on cancer stem cells. Cancer Res., 66: 933944, 2006. 


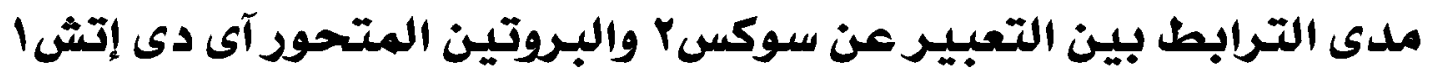

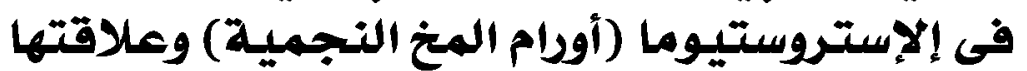

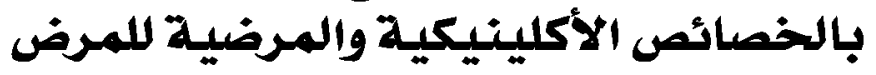

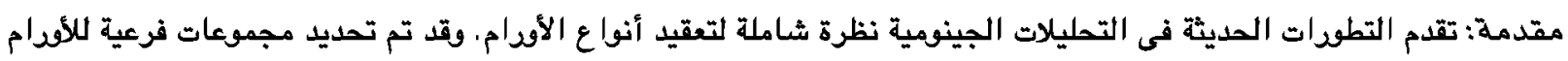

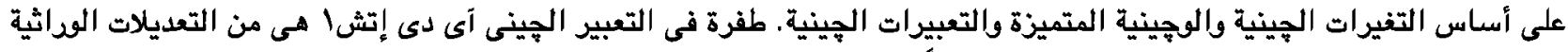

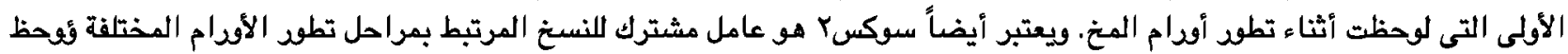

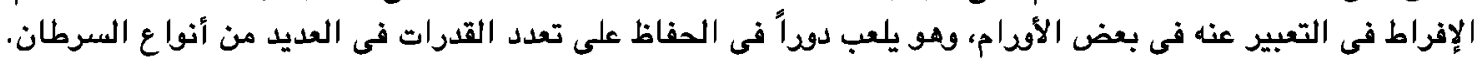

الهدف من الدراسة: دراسة مدى الترابط بين التعبير عن سوكس والبروتين المتحود آى دى إتشا فى إلإستروستيوما (أودام

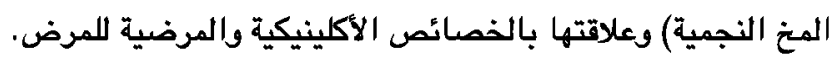

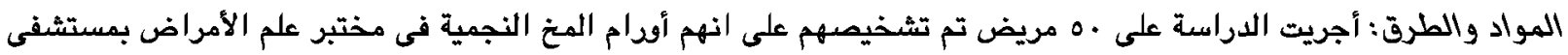

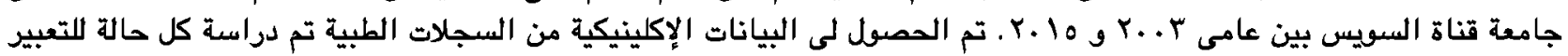

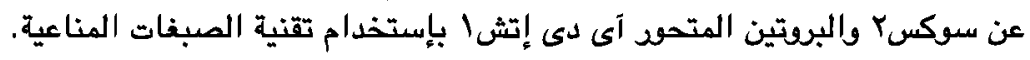

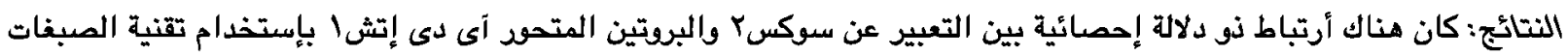

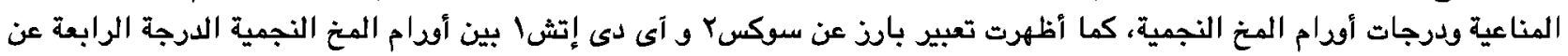

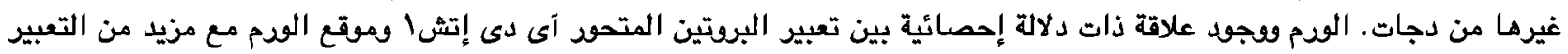

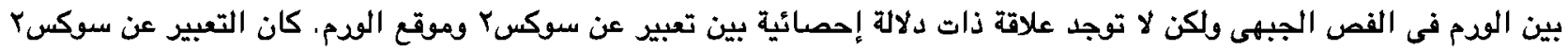

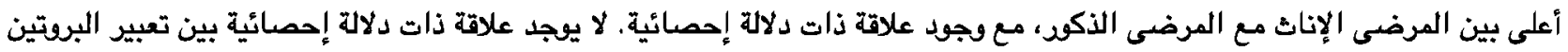

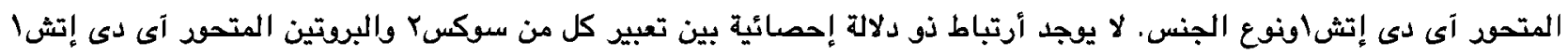

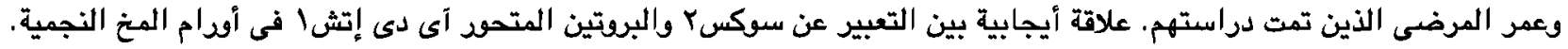

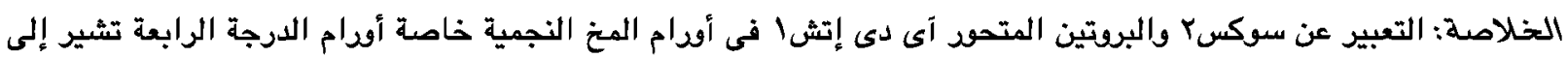

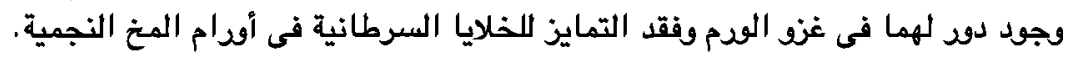

